\title{
Bilateral posterior RION after concomitant radiochemotherapy with temozolomide in a patient with glioblastoma multiforme: a case report
}

Stefanie Schreiber ${ }^{1 *}$, Vanessa Prox-Vagedes², Erck Elolf ${ }^{3}$, Ines Brueggemann ${ }^{1}$, Guenther Gademann ${ }^{4}$ Imke Galazky Claudius Bartels ${ }^{1}$

\begin{abstract}
Background: Radiation induced optic neuropathy (RION) is a rare but severe consequence of radiation therapy that is associated with adjuvant chemotherapy, specifically therapy with vincristine or nitrosoureas. However, there is very little evidence regarding the occurrence of RION after concomitant radiochemotherapy with temozolomide.

Case Presentation: The case of a 63 year old woman with glioblastoma multiforme and concomitant radiochemotherapy with temozolomide is described. Due to a slight depressive episode the patient also took hypericum perforatum. Five months after cessation of fractionated radiation and adjuvant chemotherapy with temozolomide (cumulative dose of $11040 \mathrm{mg}$ ) the patient developed bilateral amaurosis due to RION. Tumor regrowth was excluded by magnetic resonance imaging. After the application of gadolinium a pathognomonic contrast enhancement of both prechiasmatic optic nerves could be observed.
\end{abstract}

Conclusions: In this patient, the occurrence of RION may have been the result of radiosensitization by temozolomide, which could have been strengthened by hypericin. Consequently, physicians should avoid a concomitant application of hypericum perforatum and radiochemotherapy.

\section{Background}

Radiation-induced optic neuropathy (RION) is a complication of radiotherapy to the anterior visual pathway. It can occur from 3 months to more than 8 years after radiation exposure [1]. Latency to the onset of symptoms is related to the radiation dose: A total cumulative dose of fractionated radiation above $63 \mathrm{~Gy}$ is associated with an increasing risk inducing an optic neuropathy [2]. Additional predisposing risk factors are age and diabetes mellitus [2]. In addition, a pre-existing compression to the optic nerves and the chiasm may predispose these structures to injury by radiotherapy [3]. RION has been described mainly in patients with tumors of nasopharynx, paranasal sinuses, nasal cavity, pituitary adenoma, craniopharyngioma, skull base and orbita $[2,4,5]$. Since some

\footnotetext{
* Correspondence: stefanie.schreiber@med.ovgu.de

'Department of Neurology, Otto-von-Guericke University, Leipziger Straße 44, 39120 Magdeburg, Germany

Full list of author information is available at the end of the article
}

chemotherapeutic agents, namely vincristine, nitrosoureas and cisplatin [6,7] are associated with optic nerve toxicity and/or can serve as radiosensitizers [8], those patients receiving adjuvant chemotherapy have an especially high risk of developing RION.

To our knowledge, there is only one glioblastoma patient in literature who developed a left-sided optic neuropathy after concomitant radiochemotherapy with temozolomide and bevacizumab [9]. However, since there was a damage of the optic pathway as a secondary consequence of tumor growth a relation to the applied radiochemotherapy remained doubtful.

Therefore, although there is substantial literature concerned with RION, a bilateral radiation induced optic neuropathy has never been described in a patient with glioblastoma multiforme who was concomitantly treated only with temozolomide. Here, we present such a case. 


\section{Case presentation}

A 63 year old woman was presented with severe headache and psychomotor slowing that had recurred for some weeks. Her medical history revealed a mild arterial hypertension and a slight depressive episode with sleep disturbances. To treat the depressive episode the patient self-medicated with hypericin (St. John's wort, hypericum perforatum) with a dosage of $900 \mathrm{mg}$ per day, probably for several months before she was transferred to our department. No vision disorders were found. MRI revealed a contrast-enhanced $4.6 \times 3.8 \times 3.1 \mathrm{~cm}$ lesion in her right temporal lobe, with no observable compression of the optic nerves or optic chiasm (Figure 1A, B). A glioblastoma multiforme was suspected and confirmed histologically after open surgery with a resection of more than $90 \%$ of tumor tissue. After surgery, concurrent photon radiation (involved field, two co-axial isocentric fields, fractionated, once daily; cumulative dose 60 Gy, fraction size 2 Gy) and chemotherapy with temozolomide $\left(75 \mathrm{mg} / \mathrm{m}^{2}\right.$ body surface, total dose of $5040 \mathrm{mg}$ ) were implemented for a duration of 6 weeks. Target volumes and organs at risk, such as chiasm, were delineated on MRI (Figure 2A). The maximum doses to the optic nerves and chiasm were obtained from dosevolume histograms (DVHs) (Figure 2B). The maximal cumulative radiation dose of 56 Gy (maximal single dose $1.8 \mathrm{~Gy}$ ) was delivered to less than $20 \%$ of the optic chiasm. Residual parts of the optic decussation were irradiated with a median cumulative dose of $46 \mathrm{~Gy}$. Maximal cumulative dose to the right and left optic nerves were 57 Gy and 24 Gy. After starting radiation, the patient described a headache that also affected the right eye, with symptoms occurring daily and increasing during the course of the day. Karnofsky performance status [10] remained stable at about $70 \%$. Six weeks after completion of the initial course of treatment (concomitant radiochemotherapy), 4 additional cycles of chemotherapy with temozolomide $\left(150-200 \mathrm{mg} / \mathrm{m}^{2}\right.$ body surface, total dose of $6000 \mathrm{mg}$ ) were performed.

A progressive visual loss due to bilateral amaurosis occurred 5 months after cessation of radiation. This symptom was accompanied by visual hallucinations. Ophthalmological examination revealed bilateral amaurotic fixed pupils and a slightly pale optic disc. Vision loss from other causes, such as optic nerve or chiasm compression by tumor progression (MRI [Figure 3] and single photon emission computed tomography [SPECT] were performed), retinal disorders, cataract, or bilateral giant cell arteritis, were carefully excluded. Detected visual acuity was $0 / 100$ in both eyes. No visual evoked potentials could be generated by either monocular or binocular excitation with flashing lights and contrast inversions. Except for a slight elevation of protein concentration, there were no indications of infectious disease or other pathological findings in the patient's cerebrospinal fluid. Four months after RION appeared the visual loss persisted; Karnofsky performance status declined to $40 \%$.

\section{Conclusions}

Here we present the first report of a patient with glioblastoma multiforme developing a bilateral RION about
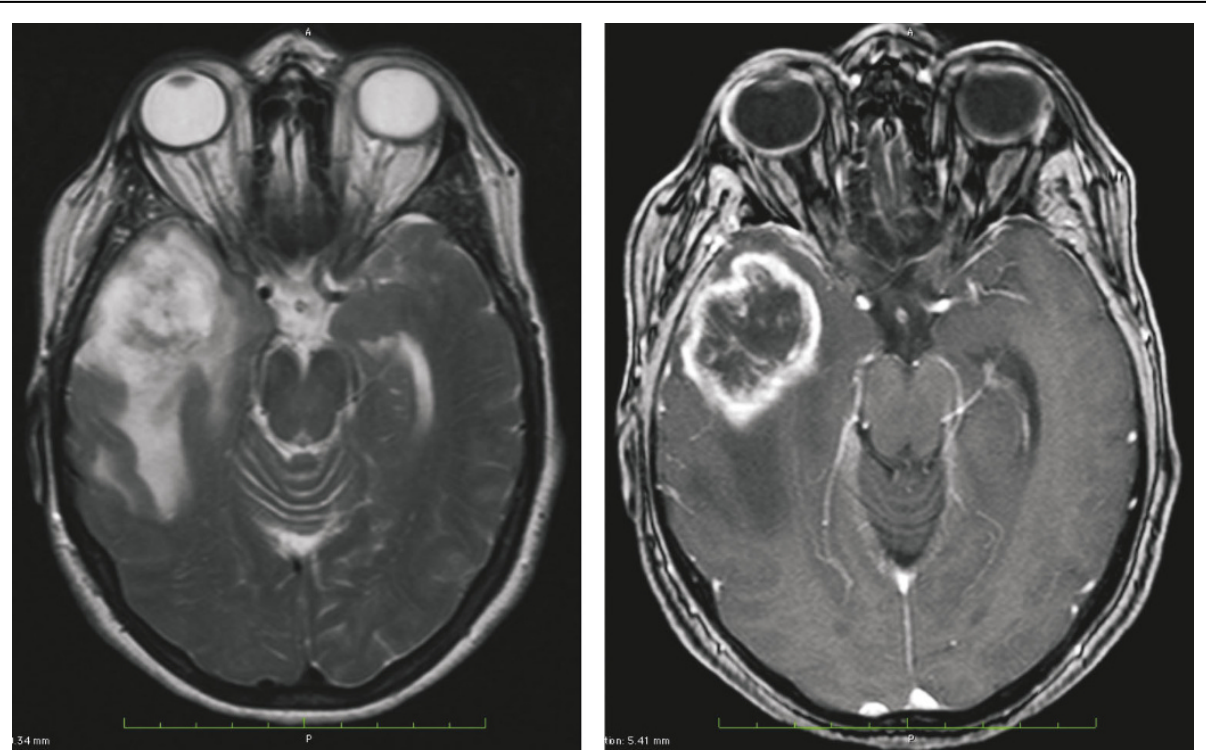

Figure 1 Images before surgery and radiochemotherapy. On T2 (Figure 1A) and gadolinium enhanced T1 (Figure 1B) weighted magnetic resonance imaging in histologically confirmed glioblastoma multiforme of the right temporal lobe can be seen. Note that there is no compression/infiltration of the adjacent optic nerve, the chiasm or the right internal carotid artery. 

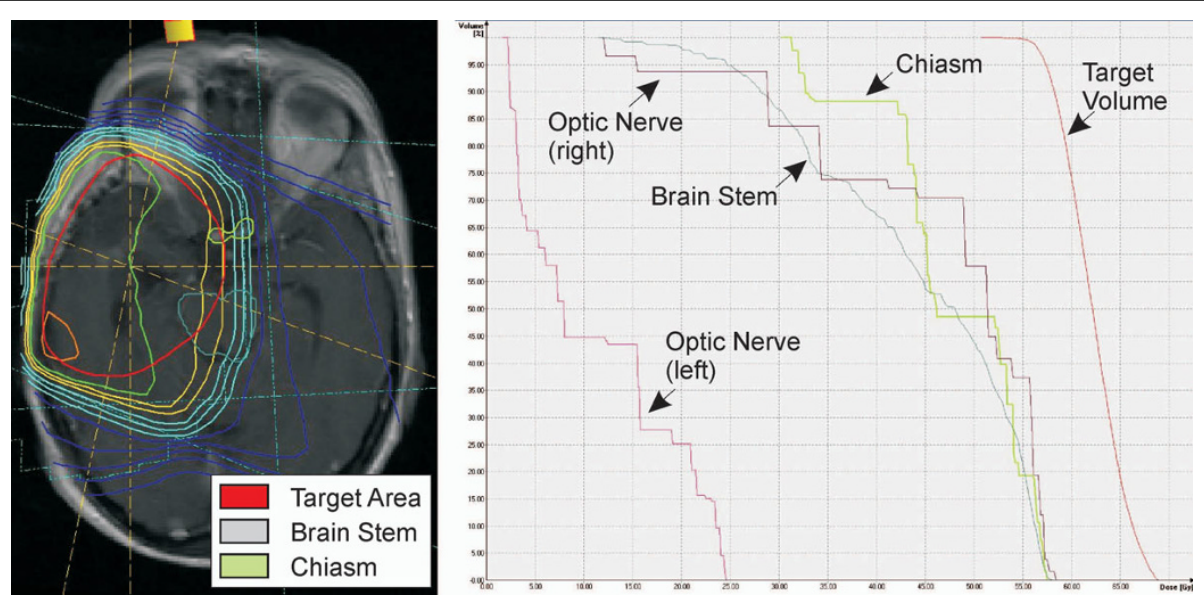

Figure 2 Target volume and dose-volume histogram. Figure 2A Magnetic resonance imaging after open surgery with isodose lines from 10 to $110 \%$. Target volume is marked in red, chiasm in green and brainstem in blue. Figure 2B Dose-volume histogram (DVH) of the radiation shows the dose given to the percentage of OAR (organ at risk) volume, i.e. less than 20\% of the chiasm was irradiated with 56 Gy within 6 weeks.

5 months after cessation of concomitant radiochemotherapy with temozolomide. An intrinsic mass in the optic nerves and/or chiasm was excluded by MRI, as was a compression of those structures by a possible recurrence of the tumor. In addition, a contrast enhancement of both prechiasmatic optic nerves could be observed after gadolinium application (Figure 3). Gadolinium enhancement of the optic nerve anywhere from its extraocular-intraorbital part to the optic chiasm seems to

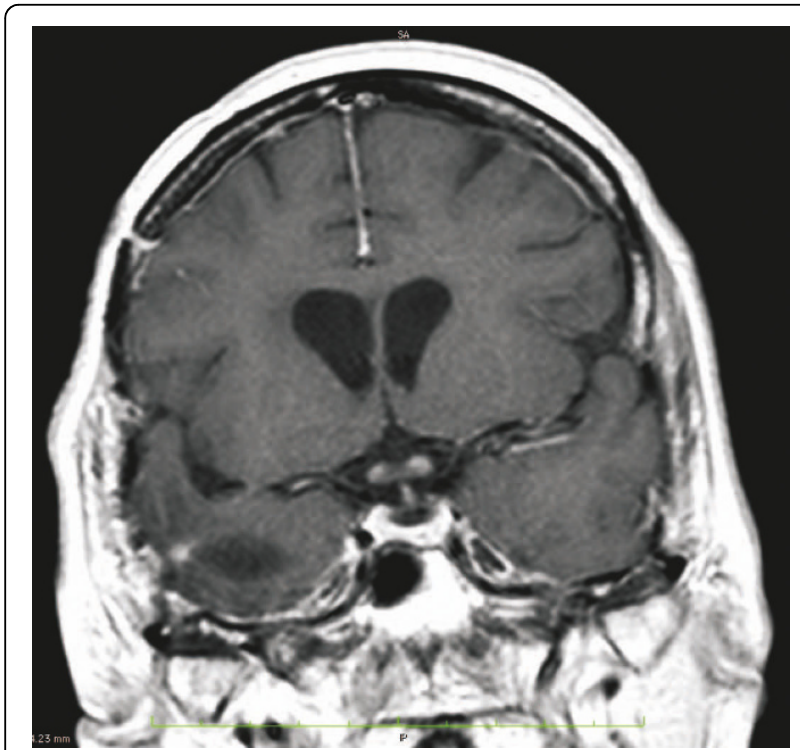

Figure $\mathbf{3}$ Images $\mathbf{5}$ months after cessation of radiation. T1 weighted gadolinium enhanced magnetic resonance imaging revealing subtle contrast enhancement of the left and right prechiasmatic optic nerve 5 months after cessation of radiation when bilateral amaurosis occurred. Note that there is no infiltration of the chiasm by tumor recurrence. be a characteristic finding of RION in MR-Imaging, since it has been described by several groups as the most common type of radiation induced optic neuropathy $[11,12]$. Accumulation of the contrast medium could be explained by a disruption of the blood-brain-barrier [5] that may play a role in the pathogenesis of RION, which is associated with delayed radionecrosis, damage and depletion of vascular endothelium and ischemic demyelination [13].

Concerning fractionated once-daily radiation, the 10year rates for freedom from optic neuropathy are respectively about $96 \%$ and $78 \%$ after the application of a total optic nerve dose of $\leq 63$ Gy and a fraction dose of $\leq 1.8$ Gy [2]. Our patient received a total cumulative dose of 60 Gy with a fraction size of 2 Gy and a maximal chiasm and optic nerve dose of 56 Gy and 57 Gy, with less than 20\% of the optic chiasm and nerves subjected to that total cumulative dose (Figure 2B). Since prescriptive limits for radiation dose were maintained, other causes that could have aggravated the radiation effect should be taken into consideration. At time of radiation the patient's age was older than 60 years, which has been depicted as significant covariate for vision loss. The patient did not suffer from diabetes, the second significant covariate for RION [4]. Female gender and arterial hypertension have not been found to be significant risk factors for radiationinduced optic neuropathy [4].

In addition, the possible effects of the patients' concomitant therapy with temozolomide and hypericin should be addressed. Interestingly, at least tumor cells undergo apoptosis when treated with photodynamic therapy sensitized with hypericin [14]. This process has been described as being associated with a cleavage of poly-[ADP-ribose]polymerase (PARP) [15], participating in cellular recovery from DNA damage [16]. An inhibition or cleavage of 
PARP might enhance the cytotoxicity of temozolomide [17] and might lead to radiosensitization [18] at least in the case of tumorcells. To what extent these processes also take place in the healthy tissue of the optic nerves and the chiasm has not been determined. However, since temozolomide is known to induce at least unilateral visual loss (summary of product characteristics by the producer of temozolomide, Essex Chemie AG, Luzern, Switzerland), produces visual loss when combined with thalidomide [19], serves as a "radiosensitizer" [8], and distributes in normal brain tissue [20], a damaging effect of temozolomide on the optic nerves/chiasm (possibly strengthened by hypericin) is conceivable.

In addition hypericin has inhibitory effects on protein kinase C (PKC) [21], which might be associated with the activation of caspases, required for radiation mediated apoptosis [21]. Hence, several preclinical studies have demonstrated that the inhibition of PKC enhances the effect of ionization radiation [22,23]. On the other hand, tissue warming caused by radiation, accelerates apoptotic effects of hypericin [24]. Thus, an additional interplay between radiation and hypericin, associated with apoptosis of endothelial cells and oligodendrocytes [25], may have occurred.

Since many patients with high-grade glioma suffer from depression, fatigue and sleep disorders [26] and since mild depressive disorders are an indication for the use of St. John's wort [27], many patients with glioblastoma multiforme may take hypericin. In view of the case of bilateral RION we report, and the aforementioned possible connection between St. John's wort and both temozolomide and the effects of radiation, physicians should be careful about administering hypericin simultaneously with radiochemotherapy.

\section{Consent}

Written informed consent could not be obtained from the patient for publication of this case report and any accompanying images because the patient has died. The patient's son has consented to publishing the data.

\section{Acknowledgements}

We thank Dr. Robert Fendrich, Dept. of Psychological and Brain Sciences, Dartmouth College, Hanover NH, USA, who proofread and copyedited the manuscript.

\footnotetext{
Author details

${ }^{1}$ Department of Neurology, Otto-von-Guericke University, Leipziger Straße 44, 39120 Magdeburg, Germany. ${ }^{2}$ Department of Psychiatry, Social Psychiatry und Psychotherapy, Hannover Medical School, Carl-Neuberg-Straße 1, 30625 Hannover, Germany. ${ }^{3}$ Department of Neuroradiology, Otto-von-Guericke University, Leipziger Straße 44, 39120 Magdeburg, Germany. ${ }^{4}$ Department of Radiation Therapy, Otto-von-Guericke University, Leipziger Straße 44, 39120 Magdeburg, Germany.
}

\section{Authors' contributions}

SS, VP and CB wrote the bulk of manuscript text and managed literature searches; SS is the corresponding author of the manuscript. IB and IG collected patients' data and documented the clinical progression. EE and GG allocated and described the MRI as well as the Dose-volume histogram. All authors read and approved the final manuscript.

\section{Competing interests}

The authors declare that they have no competing interests.

Received: 16 April 2010 Accepted: 1 October 2010

Published: 1 October 2010

\section{References}

1. Danesh-Meyer HV: Radiation-induced optic neuropathy. J Clin Neurosci 2008, 15:95-100.

2. Bhandare N, Monroe AT, Morris CG, Bhatti MT, Mendenhall WM: Does altered fractionation influence the risk of radiation-induced optic neuropathy? Int J Radiat Oncol Biol Phys 2005, 62:1070-1077.

3. Harris JR, Levene MB: Visual complications following irradiation for pituitary adenomas and craniopharyngiomas. Radiology 1976, 120:167-171.

4. Demizu Y, Murakami M, Miyawaki D, Niwa Y, Akagi T, Sasaki R, Terashima K, Suga D, Kamae I, Hishikawa Y: Analysis of Vision Loss Caused by Radiation-Induced Optic Neuropathy After Particle Therapy for Headand-Neck and Skull-Base Tumors Adjacent to Optic Nerves. Int J Radiat Oncol Biol Phys 2009, 75:1487-1492.

5. Guy J, Mancuso A, Beck R, Moster ML, Sedwick LA, Quisling RG, Rhoton AL Jr, Protzko EE, Schiffman J: Radiation-induced optic neuropathy: a magnetic resonance imaging study. J Neurosurg 1991, 74:426-432.

6. Griffin JD, Garnick MB: Eye toxicity of cancer chemotherapy: a review of the literature. Cancer 1981, 48:1539-1549.

7. Sanderson PA, Kuwabara T, Cogan DG: Optic neuropathy presumably caused by vincristine therapy. Am J Ophthalmol 1976, 81:146-150.

8. Chang JE, Khuntia D, Robins HI, Mehta MP: Radiotherapy and radiosensitizers in the treatment of glioblastoma multiforme. Clin Adv Hematol Oncol 2007, 5:894-15.

9. Lai A, Filka E, McGibbon B, Nghiemphu PL, Graham C, Yong WH, Mischel P, Liau LM, Bergsneider M, Pope W, Selch M, Cloughesy T: Phase II pilot study of bevacizumab in combination with temozolomide and regional radiation therapy for up-front treatment of patients with newly diagnosed glioblastoma multiforme: interim analysis of safety and tolerability. Int J Radiat Oncol Biol Phys 2008, 71:1372-1380.

10. Karnofsky DA, Burchenal JH, Armistead GC Jr, Southam CM, Bernstein JL, Craver LF, Rhoads CP: Triethylene melamine in the treatment of neoplastic disease; a compound with nitrogen-mustardlike activity suitable for oral and intravenous use. AMA Arch Intern Med 1951, 87:477-516.

11. Hudgins PA, Newman NJ, Dillon WP, Hoffman JC Jr: Radiation-induced optic neuropathy: characteristic appearances on gadolinium-enhanced MR. AJNR Am J Neuroradiol 1992, 13:235-238.

12. Young WC, Thornton AF, Gebarski SS, Cornblath WT: Radiation-induced optic neuropathy: correlation of MR imaging and radiation dosimetry. Radiology 1992, 185:904-907.

13. Miller NR: Radiation-induced optic neuropathy: still no treatment. Clin Experiment Ophthalmol 2004, 32:233-235.

14. Theodossiou TA, Hothersall JS, De Witte PA, Pantos A, Agostinis P: The multifaceted photocytotoxic profile of hypericin. Mol Pharm 2009, 6:1775-1789.

15. Ferenc P, Solar P, Kleban J, Mikes J, Fedorocko P: Down-regulation of Bcl-2 and Akt induced by combination of photoactivated hypericin and genistein in human breast cancer cells. J Photochem Photobiol B 2010, 98:25-34.

16. Durkacz BW, Omidiji O, Gray DA, Shall S: (ADP-ribose)n participates in DNA excision repair. Nature 1980, 283:593-596.

17. Boulton S, Pemberton LC, Porteous JK, Curtin NJ, Griffin RJ, Golding BT, Durkacz BW: Potentiation of temozolomide-induced cytotoxicity: a 
comparative study of the biological effects of poly(ADP-ribose) polymerase inhibitors. Br J Cancer 1995, 72:849-856.

18. Russo AL, Kwon HC, Burgan WE, Carter D, Beam K, Weizheng X, Zhang J, Slusher BS, Chakravarti A, Tofilon PJ, Camphausen K: In vitro and in vivo radiosensitization of glioblastoma cells by the poly (ADP-ribose) polymerase inhibitor E7016. Clin Cancer Res 2009, 15:607-612.

19. Boyar MS, Hesdorffer M, Keohan ML, Jin Z, Taub RN: Phase II Study of Temozolomide and Thalidomide in Patients with Unresectable or Metastatic Leiomyosarcoma. Sarcoma 2008, 2008:412503.

20. Rosso L, Brock CS, Gallo JM, Saleem A, Price PM, Turkheimer FE, Aboagye EO: A new model for prediction of drug distribution in tumor and normal tissues: pharmacokinetics of temozolomide in glioma patients. Cancer Res 2009, 69:120-127.

21. Datta R, Banach D, Kojima H, Talanian RV, Alnemri ES, Wong WW, Kufe DW: Activation of the CPP32 protease in apoptosis induced by 1-beta-Darabinofuranosylcytosine and other DNA-damaging agents. Blood 1996, 88:1936-1943.

22. Chmura SJ, Mauceri HJ, Advani S, Heimann R, Beckett MA, Nodzenski E, Quintans J, Kufe DW, Weichselbaum RR: Decreasing the apoptotic threshold of tumor cells through protein kinase $\mathrm{C}$ inhibition and sphingomyelinase activation increases tumor killing by ionizing radiation. Cancer Res 1997, 57:4340-4347.

23. Robins HI, Won M, Seiferheld WF, Schultz CJ, Choucair AK, Brachman DG, Demas WF, Mehta MP: Phase 2 trial of radiation plus high-dose tamoxifen for glioblastoma multiforme: RTOG protocol BR-0021. Neuro Oncol 2006, 8:47-52.

24. Karioti A, Bilia AR: Hypericins as potential leads for new therapeutics. Int $J$ Mol Sci 2010, 11:562-594.

25. Wong CS, Van der Kogel AJ: Mechanisms of radiation injury to the central nervous system: implications for neuroprotection. Mol Interv 2004, 4:273-284.

26. Fox SW, Lyon D, Farace E: Symptom clusters in patients with high-grade glioma. J Nurs Scholarsh 2007, 39:61-67.

27. Linde K: St. John's wort - an overview. Forsch Komplementmed 2009, 16:146-155.

\section{Pre-publication history}

The pre-publication history for this paper can be accessed here: http://www.biomedcentral.com/1471-2407/10/520/prepub

doi:10.1186/1471-2407-10-520

Cite this article as: Schreiber et al: Bilateral posterior RION after concomitant radiochemotherapy with temozolomide in a patient with glioblastoma multiforme: a case report. BMC Cancer 2010 10:520.

\section{Submit your next manuscript to BioMed Central and take full advantage of:}

- Convenient online submission

- Thorough peer review

- No space constraints or color figure charges

- Immediate publication on acceptance

- Inclusion in PubMed, CAS, Scopus and Google Scholar

- Research which is freely available for redistribution

Submit your manuscript at www.biomedcentral.com/submit 